\title{
LA ECONOMÍA DE TABASCO Y SU IMPACTO EN EL CRECIMIENTO URBANO DE LA CIUDAD DE Villahermosa (1960-2010)
}

\section{Tabasco's Economy and its Impact over the Urban Sprawl of Villahermosa City (1960-2010)}

\author{
Jorge Luis Capdepont-Ballina \\ Pablo Marín-Olán
}

\begin{abstract}
Resumen: El presente trabajo analiza los procesos económicos recientes de Tabasco y su impacto en el crecimiento demográfico y urbano de la ciudad de Villahermosa. La transformación de la economía de Tabasco y su capital, a raíz del descubrimiento de yacimientos de hidrocarburos en el último tercio del siglo XX, trajo como consecuencia el incremento del índice demográfico y la expansión de la mancha urbana de la ciudad, la cual se ha extendido no sólo hacia terrenos aptos para la construcción de viviendas, sino también hacia áreas de amortiguamiento o terrenos bajos inundables. Este proceso ha impactado de manera negativa en el ambiente y ha creado condiciones de vulnerabilidad física en los nuevos asentamientos humanos.
\end{abstract}

Palabras clave: crecimiento urbano, actividades económicas, demografía, impacto ambiental, vulnerabilidad.

Abstract: This work analyzes the recent economic processes of Tabasco and its impact on urban and demographic growth of the city of Villahermosa. The transformation of Tabasco's economy and its capital following the discovery of hydrocarbon deposits in the last third of the twentieth century, as a result in recent decades demographic rates increase and expansion of the urban area of the city, which has spread not only to suitable land for the construction of housing but also to buffer areas or flooded lowland, impacting negatively the environment and creating physical vulnerability conditions in the new human settlements.

Keywords: urban growth, economic activities, demography, environmental impact, vulnerability.

Jorge Luis Capdepont Ballina, doctor en historia por El Colegio de Michoacán, México. Profesor-investigador de tiempo completo de la División Académica de Ciencias Sociales y Humanidades de la Universidad Juárez Autónoma de Tabasco, México. Temas de especialización: historia regional económica e historia ambiental. Correos electrónicos: jlcapdepont@hotmail.com y jlcapdepont@yahoo.com.mx. Pablo Marín Olán, doctor en antropología social por El Colegio de Michoacán, México. Profesor-investigador de tiempo completo de la División Académica de Educación y Artes de la Universidad Juárez Autónoma de Tabasco. Temas de especialización: ecología política y cultura y educación. Correos electrónicos: pmarin@ujat.mx y marin olan@hotmail.com.
Enviado a dictamen: 17 de junio de 2013.

Aprobación: 10 de septiembre de 2013.

Revisiones: 1 . 


\section{Introducción}

L as transformaciones económicas del estado de Tabasco en los últimos 50 años han sido muy dinámicas y de importantes repercusiones sociales y ambientales. Tras el predominio del sector primario durante algunos siglos, se presentó una coyuntura histórica que favoreció el tránsito a una economía con preponderancia de la industria extractiva de hidrocarburos, hasta consolidarse en una basada en el comercio y la prestación de servicios. ${ }^{1}$

Quizá la principal característica de las nuevas circunstancias es que, a diferencia de fines del siglo XIX y la primera mitad del XX, cuando un grupo de hombres de negocios consolidaron una élite empresarial que controlaba el comercio, la posesión de tierras, la explotación de los recursos forestales, la producción agropecuaria, la banca, el transporte - marítimo, fluvial, tranvías y ferrocarriles- y otras actividades, ${ }^{2}$ en las últimas décadas del siglo XX fueron los gobierno del estado y de la federación los que promovieron cambios estructurales en los sectores productivos, quedando casi marginada la iniciativa privada tabasqueña.

Como efecto de estos procesos, la ciudad de Villahermosa ha tenido un crecimiento demográfico y urbano acelerado en las últimas décadas cuyas consecuencias son de grandes dimensiones: expansión de la mancha urbana hacia terrenos vulnerables a inundaciones, surgimiento de zonas de alta marginalidad socioeconómica, invasión de terrenos de propiedad particular y pública por personas que buscan espacios para erigir viviendas o relleno de cuerpos de agua y áreas de amortiguamiento - llamados también vasos reguladores-.

Ante la necesidad de explicar y comprender estos fenómenos, el presente trabajo tiene como objetivo el estudio del crecimiento económico, demográfico y urbano de la ciudad de Villahermosa entre 1960 y 2010, desde una perspectiva histórica, para explicar las actuales condiciones de riesgo y vulnerabilidad de la mancha urbana y su periferia. Los procesos vistos desde una óptica de larga duración nos permiten comprender las dinámicas de cambio del paisaje y sus implicaciones para la sociedad que lo propicia, de manera que se promuevan políticas públicas para mitigar los efectos nocivos sobre el ambiente acordes a las necesidades y prácticas culturales de las personas que se apropian de dicho espacio.

\section{Antecedentes}

Después de la Segunda Guerra Mundial, el gobierno mexicano se propuso superar los índices de rezago económico. El país mostró signos importantes de crecimiento, de tal modo que se alcanzó una época de prosperidad, entre 1945 y 1975 aproximadamente, que se conoce como "desarrollo estabilizador" o "milagro mexicano". En este período, las finanzas de la nación eran sanas porque el Gobierno gastaba menos de lo que ingresaba a las arcas públicas. Se procuró industrializar el país adoptando medidas proteccionistas, se abrieron oportunidades de empleo, y se mejoró la infraestructura productiva y de comunicaciones y transportes, medidas que ocasionaron un aumento del PIB de alrededor del 6\% anual durante el período (Jhabvala y Tokeshi, 1990: 14). Pese a esta tendencia, surgieron algunos problemas que se agudizarían años después porque hubo una descompensación en las políticas de fomento al privilegiarse los sectores secundario y terciario, mientras que el primario fue olvidado. Esta disposición ocasionó que se redujera la producción de materias primas y alimentos y que iniciara una constante migración del campo a la ciudad.

El gobierno mexicano enfrentaba la problemática de incentivar la producción agropecuaria no sólo para satisfacer las necesidades del país, sino también para evitar que la migración interna continuara elevándose. Por otra parte, el crecimiento demográfico de las ciudades generó una demanda de servicios públicos que con dificultad podía cubrirse, el mercado se saturó de mano de obra y se elevaron los índices de pobreza e inseguridad. En este período, quienes más se beneficiaron de la prosperidad fueron las clases media y alta, y hubo un deterioro en la calidad de vida de los más pobres, entre ellos los del campo y los grupos marginales de las ciudades. 
México contaba en 1950 con más población rural que urbana y con una economía con marcado predominio de las actividades del sector primario. ${ }^{3}$ Esta situación era similar en Tabasco (ver gráfica 1), aunque los índices económicos y sociales de crecimiento de Tabasco eran inferiores a la media nacional, sobre todo en lo que se refiere a la distribución de la población y a los sectores productivos.

En tanto los promedios del país mostraban una tendencia hacia la reducción de la vida rural, en Tabasco parecía haber un estancamiento de la urbanización; por otra parte, las actividades económicas primarias representaban casi el $76 \%$ de la base económica del estado, cuando en el país en general se había reducido hasta casi el 58\% (Capdepont, 2009: 18-19).

En los tres lustros comprendidos entre 19501964, los gastos hechos por el gobierno del estado fueron significativos y tenían como objetivos reforzar la infraestructura productiva así como la de comunicaciones y transportes, abatir los rezagos sociales, aumentar la producción en todos los sectores económicos, mejorar la calidad de vida de los habitantes y ampliar la cobertura de los servicios públicos (ver cuadro 1). Se proyectaba modernizar el estado de Tabasco, lo cual se entendía como el mejoramiento y la renovación material. Para lograrlo, se adoptaron las siguientes medidas: apertura de mayores extensiones de tierras de cultivo y de ganadería; construcción de obras hidráulicas para un mejor aprovechamiento de las tierras y el agua; promoción de nuevos métodos y técnicas para el trabajo en el campo; aplicación de incentivos fiscales para impulsar los diferentes sectores productivos; y aumento de la inversión de los gobiernos federal y local en obras y servicios públicos.

\section{El auge petrolero y su impacto en la sociedad tabasqueña}

Justo cuando en Tabasco se estaban creando las condiciones propicias para la modernización de la planta productiva y de la sociedad misma, empezaron a descubrirse y explotarse algunos yacimientos importantes de petróleo. En esa época se cuestionaba el éxito del "desarrollo estabilizador" y la desigualdad en el país, y se planteó la necesidad de buscar otras alternativas para continuar impulsando el crecimiento económico, por lo que el descubrimiento y la explotación de nuevos yacimientos petroleros en Tabasco significó la salida inmediata para las autoridades federales. Pronto todo el aparato de PEMEX se enfocó en los depósitos de hidrocarburos tabasqueños y en menos de una década el estado se convirtió en el mayor productor de petróleo y gas natural del país. Las reservas petroleras del país, que eran de unos 6000 millones de barriles en 1975, aumentaron a 60000 millones en 1980 (Tudela, 1989: 238).

En la administración de Mario Trujillo García (1971-1976) comenzó la transformación económica de la entidad, que se hizo evidente hacia 1980. La modernización, entendiéndola como un mejoramiento de la vida material de Tabasco, recibió impulso de la explotación de hidrocarburos, pero en menoscabo de la vida social y de la ecología. Las inversiones en el sector petrolero llegaron a Tabasco en mayores cantidades, de tal modo que los activos de PEMEX en la entidad aumentaron de 3200 millones a 21000 millones de pesos en 1981; en sus últimos dos informes del sexenio, el gobernador hacía hincapié en el aumento de los recursos federales, pues las participaciones federales pasaron de 21 millones de pesos en 1970 a 288 millones en 1976, y a la exorbitante cantidad de 677000 millones en 1988. Decimos exorbitante porque en 1961 los recursos aportados por la federación representaban cerca del 5\% de los ingresos del estado, pero en 1988 constituían casi el 94\% (GET, 1988a; Tudela, 1989: 240).

Al estado arribaron cientos de trabajadores de PEMEX y de compañías contratistas con sus familias, quienes demandaban más y mejores servicios; también vinieron migrantes de otras entidades atraídos por la fiebre del "oro negro" y que deseaban participar de la bonanza (Beltrán, 1998: 202). Llegaron capitales que se invirtieron en las zonas de extracción: se construyeron carreteras, caminos y puentes; se extendió la cobertura de algunos servicios como teléfono, electricidad, agua potable o alcantarillado; se pavimentaron las principales calles de varias de las cabeceras municipales; y se erigieron unidades habitacionales y fraccionamientos, 
nuevos centros educativos y de salud, así como plazas comerciales y áreas públicas de entretenimiento.

Las condiciones de la población en Tabasco no eran tan distintas de las que se observaban en el panorama nacional, e incluso puede decirse que en varios aspectos el crecimiento económico era inferior al promedio de México. En 1970 la población rural era mayor que la urbana y preponderaba la económica del sector primario, pero en 1990 esta situación ya era distinta por el repunte de las actividades secundarias - extracción de hidrocarburos - y el crecimiento urbano de las cabeceras de los municipios impactados por este sector, sobre todo Villahermosa. La infraestructura pública en todo el estado mejoró con la llegada de más recursos proveniente de las participaciones federales (INEGI, 2000a: 100-13, 310-13; 1996: 199, 258).

Elíndice de población rural de Tabasco en los censos de 1970 y 1990 estaba por arriba de la media nacional y en analfabetismo estaba cerca del promedio (ver gráfica 1). Por lo que respecta a los sectores económicos, el primario empleaba al 60\% de la mano de obra ocupada en 1970, 20 puntos porcentuales por arriba de la media del país, situación que se modificó en 1990 al reducirse a poco más del 35\%, pero aún por arriba del promedio nacional. Obviamente, estos datos son muy importantes en el contexto local porque las autoridades argumentaban que se mejoró la infraestructura urbana, se redujo el analfabetismo y se diversificaron los sectores productivos; sin embargo, destaca la pérdida de importancia del campo como generador de empleos. La aportación que hacía este rubro al PIB estatal se redujo del 48\% en 1964, a menos del 8\% en 1990, mientras que el sector secundario pasó del 5\% al 34\% en el mismo período, aunque en 1980 representó más del 83\% (GET, 1988a; INEGI, 1997: 267).

Junto a los beneficios, también se hizo presente una excesiva demanda de servicios que no podían ser cubiertos con eficiencia y calidad. Se produjo un crecimiento demográfico sin control en las zonas cercanas a los lugares de extracción de petróleo, aumentó la migración del campo a la ciudad y se descuidaron las actividades primarias, creció la inseguridad pública en las ciudades por las altas tasas de desempleo y pobreza, se acrecentó la desigualdad económica, el deterioro ecológico en los alrededores de las instalaciones petroleras se hizo evidente y, como consecuencia de lo anterior, se presentaron cambios significativos en el estilo de vida de los tabasqueños.

Al llegar al poder Leandro Rovirosa Wade (19771982), se encontró con un panorama que ningún otro gobernante de Tabasco había enfrentado: la efervescencia del petróleo. Los recursos generados por éste superaron de manera extraordinaria los que en su momento produjeron el cacao, el palo de tinte, las maderas preciosas, el plátano roatán y la ganadería. Aunque los recursos del erario estatal se habían incrementado, el problema era cómo administrarlos para superar todos los problemas que en esos momentos tenía Tabasco: mano de obra poco calificada, escasez de servicios públicos, insuficiencia productiva para satisfacer las nuevas demandas, carencias en la red de comunicaciones y transportes, rápido deterioro ecológico, llegada de migrantes en grandes números, etcétera.

Junto al impulso para consolidar una industria local, con la demanda de bienes y servicios por los efectos de la explotación de hidrocarburos, llegaron a Tabasco en 1977 varias empresas, entre las que destacan Bimbo del Sureste y Marinela del Sureste. Ese mismo año se crearon la Promotora del Complejo Agroindustrial de la Chontalpa y la Promotora del Complejo Agropecuario de los Ríos, empresas que tenían como finalidad operar los planes Chontalpa y Balancán-Tenosique, respectivamente, además de aumentar la producción de alimentos balanceados al obtener mayores volúmenes de sorgo por hectárea y caña de azúcar. También se realizó una importante inversión privada en el establecimiento de la planta de Cementos Apasco en Macuspana.

Para atraer inversiones hacia el sector secundario, el gobierno del estado impulsó el complejo Ciudad Industrial en la periferia noreste de la ciudad de Villahermosa. Se adquirieron varias hectáreas para construir una serie de bodegas que luego serían vendidas a las firmas interesadas en establecer algún tipo de industria en la entidad. Ahí se instalaron, entre otras empresas, Bimbo, Marinela, Oleaginosas del Sureste e Industrializadora de Cacao. Además de espacios para la 
ubicación de empresas, se otorgaron algunos incentivos fiscales, créditos y facilidades. Esto ocasionó que en 1982 estuvieran instaladas en la ciudad de Villahermosa 65 empresas — sólo dos de ellas existían antes de 1977-, las cuales empleaban a 4455 trabajadores y habían invertido un total aproximado de 2756 millones de pesos. Además, estaban en proceso de apertura otras 15. Por otra parte, se tenía previsto que todos los predios se vendieran en un plazo de 15 años, pero se logró en sólo ocho, de tal suerte que se planeó hacer una ampliación (GET, 1988a: 272).

La participación de la iniciativa privada fue importante en la diversificación de la industria tabasqueña, aunque debemos aclarar que sólo se abrieron empresas dedicadas al procesamiento simple de manufacturas. Varias de ellas, como Bimbo y Marinela, no adquirían sus insumos básicos en Tabasco, mientras que las compañías que trabajaban con productos locales sólo obtenían materia prima para otro tipo de industria o actividad.

Con el aumento de las necesidades básicas de los tabasqueños por el crecimiento poblacional, se tuvieron que impulsar el comercio y la banca. El primero estaba poco desarrollado dado que sólo se cubría la demanda, pero a mediados de la década de los setenta se hizo necesario ampliar el abasto, la cobertura y la calidad. Las tiendas más importantes en la entidad eran las de CONASUPO, que en 1977 tenía instalados unos 120 locales en el estado, y que en 1980 llegaron a ser 466, ubicados tanto en zonas urbanas como rurales. Además, se construyeron más mercados públicos y se erigió la Central de Abastos. También llegaron a Villahermosa algunas empresas nacionales entre las que destacan Liverpool, Chedraui, Gigante, Del Sol, Parisina y compañías automotrices. Otras ciudades beneficiadas por esta expansión de servicios fueron Cárdenas, Macuspana, Comalcalco y Huimanguillo.

Las instituciones bancarias que tenían presencia en Tabasco eran el Banco Nacional de México (BANAMEX) y el Banco de Comercio (BANCOMER), los cuales abrieron filiales en todas las cabeceras municipales. Con la fiebre del petróleo, y al haber más recursos, otras firmas hicieron acto de presencia, como BANOBRAS o BANRURAL, además de otras que sólo brindaban préstamos o seguros, como Nacional Financiera. Más tarde arribaron nuevos bancos, pero al haber una saturación del mercado terminaron por irse de la entidad o fueron absorbidos por otros grupos financieros; en 1977 había 32 sucursales bancarias y en 1982 ya eran 81 las oficinas (GET, 1988a: 276).

El escaso desarrollo de los sectores productivos no era el único problema que enfrentaba Tabasco durante el periodo de auge petrolero. En esa etapa aumentaron las demandas de servicios por el rápido crecimiento poblacional y por la incapacidad de la infraestructura local para satisfacerlas; ello se debe a que tan sólo entre 1960 y 1980 la población de Villahermosa aumentó casi el triple (ver gráfica 2). El papel del gobierno del estado fue decisivo al impulsar una política para atraer empresas que pudieran ofertar lo necesario para la nueva sociedad, de manera que las necesidades de vestuario, alimentos, muebles, material de construcción, vehículos, artículos suntuarios o bancos pudieron cubrirse, si no del todo, al menos de manera suficiente.

La bonanza tabasqueña atrajo no sólo a migrantes, sino que el estado se convirtió en un lugar con perspectiva para invertir, por lo que llegaron empresas nacionales e internacionales y, por ende, aumentó el ingreso estatal con el pago de impuestos por los distintos giros mercantiles y operaciones. Además, las exportaciones de hidrocarburos generaban grandes ganancias para el país y permitían a los gobernadores negociar con las autoridades federales mayores montos en las participaciones.

Este panorama poco cambió al asumir el gobierno Enrique González Pedrero (1983-1987). Éste se planteó como estrategia:

Sustentar el desarrollo social a través de la redistribución de la riqueza por la generación de empleos, el aumento de la producción, la organización de una sociedad más libre y el incremento de las medidas de gobierno para la justicia y la seguridad sociales (González, 1983: III).

Para lograrlo, se debía impulsar el cambio estructural en los sectores económicos, modificar las tendencias 
de urbanización e industria y dar mayor fortaleza a la autonomía municipal. El primer punto implicaba lograr una producción de bienes y servicios suficiente para satisfacer las necesidades básicas de la población, mejorar con esto su calidad de vida y lograr un verdadero crecimiento. El segundo punto se refiere a un orden y planificación que impidiera el desequilibrio entre el aumento demográfico y la oferta de servicios públicos, además de fomentar las otras ramas del sector industrial para no seguir dependiendo del petróleo. Y, finalmente, el tercer punto tenía como prioridad otorgar a los municipios la capacidad de generar sus propios recursos y libertad para administrar los bienes de acuerdo a sus necesidades (González, 1983: III-VII, 19 y 41-58).

Nuevos retos tendrían que enfrentar los sucesivos gobernantes tabasqueños (Salvador Neme Castillo [1989-1991], Manuel Gurría Ordoñez [1991-1994] y Roberto Madrazo Pintado [1994-2000]). La baja en la producción de hidrocarburos y la inseguridad se sumaron a los añejos problemas del campo, a la escasa industrialización, a los altos índices demográficos y a la insuficiencia de los servicios. Se inició una paulatina transformación de la economía tabasqueña que pasó de ser dependiente de la extracción de hidrocarburos a prestadora de servicios.

\section{Transformación económica y demográfica: Villahermosa, de pueblo a ciudad}

Al arribar el siglo XX, la sociedad tabasqueña mostraba una gran diferencia entre los grupos sociales, pero esto no impedía que cada uno de ellos tuviera espacios propios de esparcimiento e incluso que compartieran algunos. En San Juan Bautista - hoy Villahermosase tenía una calidad de vida mejor que en el resto de Tabasco, ya que era el lugar al que llegaban las novedades tecnológicas, así como modas y estilos de vida que se importaban de Europa — principalmente de Francia e Inglaterra - y de Estados Unidos. Ahí se encontraban albergadas las autoridades del estado, las principales casas mercantiles - entre otras, Berreteaga y Compañía, Ripoll y Compañía, G. Benito y Compañía, La Ciudad de México, Juan Ferrer y Compañía-, los mejores colegios y sanatorios, y una buena parte de los dueños del capital.

San Juan Bautista había crecido a orillas del río Grijalva, de manera que hacia 1900 apenas superaba los 10000 habitantes, siendo el principal centro poblacional de Tabasco. Otras localidades importantes eran Frontera, que no llegaba a 3000 pobladores, y Cárdenas y Huimanguillo, que tenían poco más de 2000 (Capdepont, 2010: 60). Sólo tenía algunas calles empedradas y la mayor parte eran de terracería; la vivienda popular en general no representó un gran problema para el contexto local puesto que, al ser un estado con una cifra bastante modesta de habitantes, no había mucha presión en la demanda. No se dispone de cifras de principios del siglo XX, pero para 1930 cerca del 76.9\% de las viviendas en Tabasco estaba construido con materiales no duraderos, cifra que se redujo al 56\% en 1950, al aumentar las construcciones hechas con ladrillo, block, piedra o cemento (INEGI, 1996). La casi totalidad de los tabasqueños disponía de un espacio para habitar y no había necesidad de programas sociales para financiamiento de viviendas, pero las cosas cambiaron radicalmente en la segunda mitad de esa centuria.

Tabasco seguía careciendo de carreteras en buenas condiciones que contribuyeran a un mejor desplazamiento de mercancías y personas hacia el interior y exterior, puesto que todavía predominaba el transporte fluvial y marítimo; además, se padecían constantes inundaciones en la capital y en algunas zonas productivas, lo que afectaba seriamente la economía local. El estado seguía dependiendo del sector primario y poco se habían desarrollado las actividades secundarias y terciarias; por ejemplo, la disponibilidad de los servicios públicos se centraba en las cabeceras municipales, sobre todo en Villahermosa. Bajo este panorama se arribó a la segunda mitad del siglo XX y constituyó un reto para las autoridades superar estas problemáticas; a la par, una serie de procesos comenzó a gestarse y sería de gran trascendencia en la transformación violenta de la economía local, cuyo impacto fue de dimensiones considerables en las políticas públicas, los sectores productivos, la urbanización, la sociedad y la cultura. 
A principios del período 1971-80 comenzaron a descubrirse nuevos yacimientos de hidrocarburos en Tabasco, de manera que se produjo un periodo de transición de una economía con preponderancia del sector agropecuario hacia una economía dependiente de la extracción de hidrocarburos, lo cual, no sólo mantenía la desarticulación productiva del estado, sino que poco a poco dividía la entidad en dos grandes regiones, agudizaba la marginación social en el campo y las ciudades, segregaba las actividades primarias y propiciaba un rápido deterioro ecológico en las cercanías de las zonas de extracción.

Los gobiernos estatal y municipal de laépoca tuvieron un interés constante en mejorar la infraestructura urbana así como en satisfacer las demandas sociales de servicios públicos. Para ello, se hicieron importantes inversiones en vivienda, educación, salud, energía eléctrica, agua potable y alcantarillado (ver cuadros ly3). En educación se sostenía que los principales problemas eran el escaso presupuesto, insuficientes escuelas, falta de maestros, deficiente formación de los profesores, poca infraestructura escolar, deserción y ausentismo, por lo que, para superar el rezago, se aumentaron los recursos, se procuró mejorar la formación de los profesores, se creó nueva infraestructura y los otros servicios también ampliaron su capacidad de atención a la sociedad tabasqueña, tanto urbana como rural (Beltrán, 1998).

Si bien durante la administración de Carlos A. Madrazo (1959-1964) se impulsó la construcción de obras de embellecimiento de Villahermosa, así como de infraestructura vial y educativa, de recreación cultural y administrativa - como la Ciudad Universitaria de la UJAT, la Ciudad Deportiva, el nuevo hospital Juan Graham Casasús, los puentes de La Pigua y Los Monos-, mercados, avenidas o parques, fue con el auge del petróleo cuando se dispuso de mayores recursos para hacer de la capital de Tabasco una verdadera ciudad, pues hasta mediados del siglo XX era considerada por los visitantes como un gran pueblo. ${ }^{4}$

La mayor presión se concentró en los servicios públicos como vivienda, educación, salud, energía eléctrica, agua potable, alcantarillado, comunicaciones $\mathrm{y}$ transportes $\mathrm{y}$, por si fuera poco, inseguridad y desempleo, problemas nuevos para la planicie tabasqueña. La ciudad, que había comenzado a extenderse en la margen derecha del río Grijalva frente a Villahermosa-, aceleró este proceso después de 1960 y se fueron ocupando terrenos bajos que servían de áreas de amortiguamiento en el desborde de ríos y lagunas — vasos reguladores-. Colonias populares como Las Gaviotas, La Manga, Casablanca, los Espejos I y II y Los Carrizales se asentaron en zonas de riesgo que recibieron un fuerte impacto en las inundaciones de 1982 y 1999. En este proceso de expansión de la mancha urbana, los antiguos pueblos de Atasta, Tamulté y Tierra Colorada fueron absorbidos por la ciudad y se convirtieron en colonias.

Entre 1970 y 1990, se erigieron en Villahermosa el complejo comercial, de negocios, turístico y habitacional Tabasco 2000 —donde se ubican las Galerías Tabasco 2000, hoy Galerías Tabasco, unidades habitacionales como Nueva Imagen, Multi 80, Los Ríos, colonia Petrolera, Campestre o Carrizal, el palacio municipal de Centro, el planetario, el centro administrativo, el club Campestre, el parque La Choca y algunos hoteles-, la Ciudad Industrial, la colonia popular INDECO, el aeropuerto internacional, el periférico, los palacios de los poderes legislativo y judicial, hospitales, escuelas, mercados, el teatro del estado, el Centro de Investigación de las Cultura Olmeca y Maya (CICOM), museos, el parque zoológico Yumká, glorietas, fuentes, puentes y pasos a desnivel, entre otras obras de gran importancia. Surgieron nuevas colonias y algunas aumentaron en número de viviendas y fraccionamientos, como Casablanca, Espejos ly 2, Heriberto Kehoe, Electricistas, Lindavista, Atasta, Tamulté, Magisterial, Lidia Esther y Arboledas, entre muchas otras. ${ }^{5}$ Con esta infraestructura se le dio a Villahermosa un estilo contemporáneo, a diferencia de otras capitales del sureste que tienen rasgos coloniales, como Campeche o Mérida.

\section{Los años recientes: Villahermosa, ciudad próspera y vulnerable}

Hacia 1990 comenzó a disminuir la extracción de hidrocarburos en Tabasco, a la par que nuevos 
yacimientos habían sido descubiertos en Veracruz y Campeche. La economía tabasqueña tenía serios problemas por el estancamiento notable en las actividades primarias e inclusive en la industria de manufacturas. Con la caída de los volúmenes de la producción y los precios de los recursos petrolíferos en los mercados internacionales, los sucesivos gobiernos tabasqueños se vieron en la necesidad de adoptar nuevas medidas para diversificar las actividades productivas. La situación no ha sido fácil porque durante el periodo del auge petrolero, y en las últimas décadas, el crecimiento demográfico ha sido constante y a veces acelerado, lo cual trajo consigo una mayor demanda de servicios, un aumento de los índices de inseguridad pública y la agudización de la desigualdad social.

Ya desde la administración de González Pedrero se advertía sobre los problemas ocasionados por la industria petrolera en la economía, la sociedad y el medioambiente de Tabasco. Se consideraba que el estado había sido dividido en dos grandes zonas muy diferentes entre sí. Por un lado estaba la cuenca del río Grijalva, que aglutinaba los municipios de las subregiones Centro, Chontalpa y Sierra. Esta región tenía un crecimiento más acelerado de población y de los índices económicos y una mayor subordinación a la explotación de hidrocarburos. Por otro lado se encontraba la cuenca del río Usumacinta, conformada por los municipios de la subregión Ríos, que tenía escasa población, asentamientos dispersos, relativo aislamiento y dependencia del sector agropecuario (González, 1983: VII).

De acuerdo con los datos demográficos de 1990, se observa que fueron pocos los cambios en los índices de crecimiento económico. Quizá los principales a nivel nacional y local fueron la reducción del número de habitantes rurales, el decrecimiento de la participación del campo en el PIB y la ampliación de la cobertura de algunos servicios en las zonas urbanas (ver cuadro 3 y gráficas 1 y 2). Por otra parte, se agudizaron las desigualdades entre el campo y la ciudad, e incluso entre los grupos sociales, creció el índice de inseguridad y la gravedad de los delitos, la tasa de desempleo se incrementó y hubo pérdida del poder adquisitivo provocada por las altas tasas de inflación y el poco aumento de los salarios, sobre todo en la clase trabajadora.

Frente a la dinámica que estaba imponiéndose con el estancamiento y la posterior caída de la producción petrolera en Tabasco, los gobiernos locales de las dos últimas décadas tuvieron que trazar otras alternativas para impulsar el crecimiento económico del estado. Una de ellas fue ajustarse al Plan nacional de desarrollo y al modelo neoliberal promovido por Carlos Salinas de Gortari y continuado por Ernesto Zedillo, Vicente Fox y Felipe Calderón. Se modificó también la política económica interna seguida por los gobiernos locales entre 1970 y 1988. Como resultado del modelo económico neoliberal, ya no es la tierra la que proporciona los mayores recursos, sino el sector secundario con el 63.8\% y el terciario con el 34.6\% (ver cuadro 2).

Con la política de libre comercio y el interés del gobierno local por transformar la economía en prestadora de servicios y centro de negocios, a la capital de Tabasco llegaron entre 1991-2012 inversiones de importantes firmas, como las del grupo Walt-Mart Aurrerá, The Home Depot, Suburbia, Walt-Mart, Sam's Club, Vips, El Portón-, Soriana, Del Sol, Parisina, Modatelas, Chedraui, Sanborn's, Officce Depot, Liverpool, Palacio de Hierro, Sears, Fábricas de Francia, City Club, Elektra, Coppel, C\& A, Farmacias del Ahorro, Farmacias Unión, Farmacias Yza, Cinépolis, Cinemex y Comercial Mexicana. Aumentaron las inversiones de las compañías de telecomunicaciones - Telcel, Iusacell, Nextel, Movistar, Sky, Cablecom, Televisa, TV Azteca, etcétera-y empresas de seguros. También los bancos abrieron nuevas sucursales.

Estas grandes firmas crearon la posibilidad de ofrecer mejores precios a los consumidores, pero desplazaron a las compañías abarroteras que desde hacía mucho tiempo distribuían mercancías a mediomayoreo y mayoreo, no sólo en la capital de Tabasco, sino también en los demás municipios. Varias de estas cadenas, así como las abarroteras desplazadas de Villahermosa, se desplazaron a otros municipios, abriendo nuevas oportunidades de empleo, pero ocasionando que pequeñas y medianas tiendas 
familiares cerraran sus puertas por no poder competir con capitales más grandes. Dejaron sin trabajo no sólo a los dueños, sino también a los pocos dependientes que en ellas laboraban.

Con lo anterior se constata la importancia que tiene el sector terciario en la economía de Tabasco, puesto que no sólo absorbe la mayor parte de las inversiones, sino que también constituye la principal fuente de trabajo y una de las mayores fuentes de ingresos en el estado. El sector primario, que en 1970 representaba el 19.5\% del PIB de Tabasco, redujo su importancia en la economía local a tan sólo el 3.8\% en 1980, mientras que el secundario aumentó su relevancia del 39.2\% al 83.4\% en el mismo período. Destaca la actividad petrolera, que tuvo un boom a mediados de la década referida (INEGI, 1997, 2001, 2008 y 2012). Pese a las políticas implementadas por las sucesivas administraciones públicas del estado para impulsar el crecimiento de la agricultura y la ganadería, éstas no han tenido el éxito esperado y la tendencia decreciente de las actividades primarias no ha variado en gran medida dado que en el pasado año (2012) representaban sólo el 1.6\% del PIB (ver cuadro 2).

Elimpactodelaindustria extractiva de hidrocarburos en el crecimiento demográfico de Tabasco no tiene precedentes, y donde se refleja con mayor claridad es en el municipio de Centro, específicamente en la ciudad de Villahermosa (ver gráfica 2). Si entre 1960 y 1980 la población de la capital tabasqueña se triplicó, entre 1980 y 2010 se duplicó. Este proceso implicó la demanda de servicios que los gobiernos y la iniciativa privada locales no estaban preparados para satisfacer; de ahí que en este periodo aumentaran las inversiones foráneas -nacionales y extranjeras - en el estado, al grado de transformar Villahermosa de un gran pueblo a una ciudad moderna en tan sólo unos años.

La mancha urbana de Villahermosa, que inició una expansión acelerada en el último cuarto del siglo XX, mantiene el mismo ritmo en la actualidad. Sin embargo, ahora no es sólo por el impacto de la industria de hidrocarburos, sino también por la variedad, cantidad y calidad de los servicios que se han concentrado en esta capital. Plazas comerciales, educación privada y pública, lugares para entretenimiento, agencias automotrices, especialidades médicas o fuentes de empleo, son los atractivos para los nuevos pobladores, sobre todo para los jóvenes procedentes del resto de los municipios e incluso de los estados vecinos. La movilidad económica y de servicios hacen de Villahermosa una de las ciudades de mayor proyección financiera y urbana en el sureste de México (GET, 2007: 183-184).

Si bien es cierto que Villahermosa se proyecta como un foco financiero importante en el sureste mexicano, también enfrenta serios problemas por la presencia de tres tendencias territoriales que crean condiciones de posibilidad para la emergencia de la vulnerabilidad (Marín, 2013). La primera tendencia es la construcción de infraestructura hidráulica que comprende un amplio sistema de bordos y puentes para la protección de la ciudad a raíz de los desastres ocurridos en las inundaciones de 1999, 2007 y 2008. Estas obras, diseñadas para el control de los ríos, no sólo han modificado el espacio de la fase periurbana, ${ }^{6}$ sino también las formas de acceso a los recursos y las relaciones intralocales.

La segunda tendencia son las exploraciones llevadas a cabo por PEMEX al occidente del río Tepaté —río Pichucalco-, que se une con el río de la Sierra a la altura de la población La Majahua, para desembocar juntos en el río Grijalva. La trayectoria de ambos ríos antes de su desembocadura en el Grijalva se encuentra rodeada por un vasto sistema lagunar interconectado.

Una tercera tendencia la constituyen los planes de desarrollo de viviendas orientados hacia los corredores Villahermosa-Ocuiltzapotlán (carretera a Frontera), Villahermosa-Dos Montes (carretera a Macuspana) y Villahermosa-Parrilla (carretera a Teapa). Sin embargo, en estas zonas existe un complejo sistema de cuerpos lagunares que sirve para regular los volúmenes de agua procedentes del río de la Sierra y del río Grijalva, muchos de los cuales se han modificado no sólo en tamaño, sino que también han mostrado una reducción en su profundidad de hasta 50 centímetros, alterando los niveles topográficos y de escurrimientos (Marín, Capdepont y Díaz, 2012).

Al coexistir estas tendencias territoriales en un mismo espacio y tiempo, se ha generado un ambiente de tensión e incertidumbre entre las poblaciones 
aledañas a los cuerpos lagunares periurbanos - muchas de ellas dedicadas históricamente a la pesca-, ya que la construcción de infraestructura hidráulica ha modificado los cursos naturales y los niveles hídricos de las lagunas por la reciente sedimentación. Ante esta modificación de los paisajes periurbanos, muchas poblaciones han recurrido a estrategias de adaptación y a formas de organización social ${ }^{7}$ que les han permitido coexistir con las nuevas modalidades de ordenamiento territorial.

Ante la escasez de terrenos propicios para zonas habitacionales y comerciales, el ayuntamiento del municipio de Centro ha proyectado impulsar tres focos de crecimiento urbano (ver mapa 1) para conformar tres ciudades satélite que permitan aliviar la presión demográfica y la expansión urbana de la capital tabasqueña (IMPLAN, 2011).

Los recientes complejos habitacionales y la construcción de bordos de contención no sólo han modificado el paisaje de la ciudad de Villahermosa, sino que también han provocado un fenómeno de asentamientos irregulares en las márgenes de los fraccionamientos y sobre los mismos bordos de contención (Marín, Capdepont y Díaz, 2012). En el caso del asentamiento de pobladores en las márgenes de los nuevos fraccionamientos, éste se debe a que varias compañías que adquirieron los terrenos para fraccionar presentaron irregularidades en los levantamientos y planos finales; así, muchos de los espacios destinados para recreación y áreas verdes fueron ocupados desde 2005 por familias sin hogar procedentes de Gaviotas Sur, Gaviotas Norte, Tierra Colorada y Bosques de Saloya (Nacajuca), tendencia que se agudizó después de la inundación de 2007.

Al indagar sobre los motivos que propiciaron el poblamiento de espacios controlados por empresas dedicadas al fraccionamiento y la construcción, descubrimos que la ocupación de "terrenos vacíos" fue una idea que se originó - al menos en el asentamiento conocido como Las Escobas- por redes familiares y congregaciones religiosas con liderazgos provenientes de capas populares.
Fui a una campaña de un movimiento Cristiano, pasé al llamamiento y le conté a mi mentor los problemas que tenía, me habló de esta zona como una solución temporal mientras salía de mis deudas, también me puso en contacto con una viejita que era dueña de la casita vieja que había antes aquí. Dijo que mi vida cambiaría radicalmente, lo dudé, pero no me mintió, todo está mejor desde entonces, Dios me ha prosperado, tengo casa, tienda y ojalá que pronto esto sea ya de mi propiedad (Santos Chávez, 14 de marzo de 2011). ${ }^{8}$

Tras la inundación de 2007 se incrementó el número de familias asentadas de manera irregular. A diferencia de los primeros asentamientos de 2005, donde se reconocía el liderazgo religioso para validarlos, en la actualidad el poder de organización es representado por dirigentes civiles que construyeron su liderazgo a partir de filiaciones políticas, aprovechando la coyuntura previa al proceso electoral para elegir al alcalde del municipio de Centro. Estos liderazgos propiciaron tensiones entre los pobladores y un cuestionamiento hacia la legitimidad de los líderes que habían acaparado varios predios para comercializarlos.

La incertidumbre sobre la posesión ilegal ha ido en aumento desde que los líderes comunitarios informaron a los habitantes que los predios no serían regularizados por encontrarse en una zona de riesgo. Sin embargo, estos grupos han desdoblado este argumento oficial y han elaborado una defensa inteligente al argumentar que nunca han existido históricamente cuerpos lagunares en la zona de asentamiento para que ésta sea considerada de riesgo; más bien, estos depósitos de agua que asemejan lagunas han sido producto de las excavaciones hechas por las compañías constructoras para obtener material de relleno y de construcción, de manera que todo se debe a una medida de presión hecha por el gobierno para que abandonen sus hogares.

Estas irrupciones en el tejido social son algunos de los efectos producidos por las tendencias territoriales arriba descritas. Si bien se ha trabajado desde el punto de vista técnico para proteger con infraestructura hidráulica la ciudad de Villahermosa, no se ha realizado 
hasta la fecha un estudio de impacto ecológico y social de estas medidas ingenieriles. Los muros de contención construidos para defender la mancha urbana de las inundaciones, no sólo impiden la entrada de un elemento natural asociado históricamente al hombre de las tierras bajas, sino que también impiden ver al "urbanita" (Simmel, 2005) el encuentro violento de su mundo interno y la urbanización de su entorno, al percatarse de que a escasos diez kilómetros detrás de los muros existen sociedades rurales que ahora son depositarias de sus miedos y pesadillas.

\section{Conclusiones}

El siglo XX en Tabasco estuvo marcado por cambios significativos en su estructura productiva. De ser un estado con predominancia primero agrícola y luego pecuaria, en el último tercio de esta centuria se consolidó el sector secundario - específicamente la industria extractiva de hidrocarburos - como la base de la economía, y en las dos últimas décadas se produjo un paulatino equilibrio entre este rubro y el terciario - comercio y servicios-. Estos procesos generaron también transformaciones en el ritmo de crecimiento demográfico y urbano de la entidad que se reflejan sobre todo en la ciudad de Villahermosa, que entre 1950 y 2010 aumentó su población de 33578 a 353577 habitantes, poco más de diez veces.

Con el crecimiento demográfico acelerado de Villahermosa comenzaron a presentarse serios problemas en el desarrollo urbano. La ciudad se extendió y se agotaron los terrenos óptimos para la construcción de viviendas, plazas comerciales y áreas de esparcimiento. Cabe aclarar que el promedio de altura del suelo donde está asentada Villahermosa y su área conurbada es de 12 metros sobre el nivel del mar, con picos que llegan a los 20 metros; en general, estos terrenos pertenecen a las tierras bajas de la llanura costera del Golfo de México, que se caracterizan por ser bajos, de escasa permeabilidad y susceptibles de inundación; esta situación ha condicionado el desarrollo urbano de la capital tabasqueña, pero no lo ha limitado.
Ante la presión demográfica y la escasez de viviendas y servicios, así como de suelos óptimos para asentamientos humanos, terrenos bajos han sido rellenados para la construcción de unidades habitacionales y plazas comerciales. Antiguas áreas de amortiguamiento - donde en temporada de crecientes desbordaban ríos y lagunas - fueron reducidas en número y espacio, poniendo en peligro de inundación a miles de personas y cuantiosos bienes materiales. Si bien las crecientes anuales forman parte de la vida cotidiana de Tabasco, las presentadas en la ciudad de Villahermosa en la segunda mitad del siglo XX y la primera década del XXI han sido de graves consecuencias sociales y económicas, sobre todo las de 1952, 1980, 1999 y 2007.

Las autoridades estatales y municipales han comenzado a establecer lineamientos para el ordenamiento territorial y ecológico, pero quedan muchas lagunas en la legislación que son aprovechadas por las compañías constructoras y por particulares para continuar con la dinámica del crecimiento urbano desordenado y sin una perspectiva de protección ambiental y de control de riesgos o vulnerabilidad. Estos desacuerdos en materia legal y de competencia jurídica conducen a distintos puntos de vista respecto a los proyectos urbanísticos; por ejemplo, el ayuntamiento del municipio de Centro planea impulsar tres ciudades satélite alrededor de Villahermosa: en Ocuiltzapotlán, Dos Montes y Parrilla (ver mapa 1).

Aunque estos proyectos son necesarios, no se han tomado acuerdos entre las dependencias municipales y estatales para evaluar las consecuencias económicas, sociales, políticas y ambientales. Se han presentado los estudios de factibilidad de suelos para la construcción de viviendas, áreas comerciales y de entretenimiento, zonas escolares e instituciones de gobierno; sin embargo, no son muy claros los estudios de impacto ambiental — control de desechos o equilibrio ecológico - ni socioeconómicos - uso de suelos o actividades económicas - Desafortunadamente, ya se ha empezado la construcción de complejos habitacionales hacia Parrilla y Dos Montes, con graves consecuencias para los cuerpos de agua, flora y fauna de estos lugares. 
Las acciones legales de las autoridades contra el daño ecológico están ausentes.

Mucho se tiene que discutir sobre esta problemática porque, a los problemas generados por el crecimiento urbano desordenado, como la creación de zonas de vulnerabilidad a inundaciones, se añadeel dañoecológico que causan el relleno de áreas de amortiguamiento y la generación de desechos sólidos que son descargados a los cuerpos de agua.

\section{Notas}

${ }^{1}$ Esteartículoes resultadodirectodel subproyecto "Estudios para la identificación de áreas de amortiguamiento y protección ecológica", coordinado por el Dr. Miguel Ángel Díaz Perera de El Colegio de la Frontera Sur-Unidad Villahermosa, dentro del proyecto "Gestión y estrategias de manejo sustentable para el desarrollo regional en la cuenca hidrográfica transfronteriza Grijalva", con financiamiento del Fondo Institucional de Fomento Regional para el Desarrollo Científico, Tecnológico y de Innovación (FORDECyT), clave 143303.

${ }^{2}$ Esta etapa en la historia de Tabasco estuvo caracterizada por un impulso a la economía de la entidad debido a una coyuntura de expansión capitalista y de consumo de algunos países europeos y Estados Unidos.

${ }^{3}$ En el sector primario se incluyen la agricultura, ganadería, silvicultura, caza y pesca; en el secundario la minería, extracción de petróleo y gas, industria manufacturera, generación de energía eléctrica y construcción; y en el terciario el comercio y los servicios.

${ }^{4}$ El parque museo La Venta en la ciudad de Villahermosa había sido inaugurado en marzo de 1958.

${ }^{5}$ También se remodelaron obras existentes como el parque Tabasco - luego parque Tomás Garrido Canabal-, el mercado Pino Suárez, la Plaza de Armas, el palacio de gobierno del estado, el malecón, etcétera (GET, 1988: vols. 9-14)

${ }^{6}$ La concepción del espacio periurbano (IPU) ha sido asociada con la periferia de la ciudad en función de sus rasgos morfológicos y funcionales. Su implicación es que la IPU comprende las áreas que rodean la ciudad y se encuentran en proceso de urbanizarse. La proximidad a las áreas urbanas y la ausencia de atributos urbanos, como infraestructura urbana son los criterios que subyacen a esta definición (Allen, 2003).

${ }^{7}$ El reavivamiento del sistema de cooperativas en esta zona sur ha sido una estrategia adaptativa ante la reconfiguración de la propiedad privada. Tanto las cooperativas oficiales, como aquellas que han escapado al "control" gubernamental, pueden leerse como formas de organización social efectivas para negociar las reglas de acceso a los recursos ante el Estado y los grandes propietarios. Así también, las nuevas formas cooperativistas que van desde las agrupaciones que no se someten al control oficial, hasta aquellas que abren sus puertas para la especulación financiera, nos muestran los matices de las estrategias creativas que están desplegando los grupos, que de alguna forma han sido invisibilizados por la implementación de proyectos hidráulicos y de urbanización (Marín, Capdepont y Díaz, 2012).

${ }^{8}$ Entrevista realizada a María del Carmen Santos Chávez, 14 de marzo de 2011 en Las Escobas, Villahermosa, Tabasco, México.

\section{Referencias bibliográficas}

Allen, Adriana (2003), "La interfase periurbana como escenario de cambio y acción hacia la sustentabilidad del desarrollo", en Cuadernos del Cendes, vol. 20, núm. 53, mayo, pp. 7-21. 〈http://www.scielo.org.ve/scielo. php?pid=S1012-25082003000200002\&script $=$ sci arttext> [20 de julio de 2013].

Ayuntamiento de Centro (2009), Prontuario estadístico municipal de Centro, Villahermosa: Ayuntamiento de Centro-Secretaría Técnica.

Beltrán, José Eduardo (1998), Petróleo y desarrollo, México: EDYCAR.

Capdepont Ballina, Jorge Luis (2009), "Del campo a la ciudad. Tabasco y sus transformaciones económicas (1945-2008)", en Carlos E. Ruiz Abreu y Andrés Fábregas Puig (coords.), Historia política contemporánea de Tabasco, 1958-2008, t. 2. Villahermosa: Gobierno del Estado de Tabasco, pp. 1-115.

Capdepont Ballina, Jorge Luis (2010), "Tabasco en la segunda mitad del siglo XIX", en Carlos E. Ruiz 
Abreu y Andrés Fábregas Puig (coords.), Historia del palacio de gobierno de Tabasco (1884-2010), Villahermosa: Gobierno del Estado de Tabasco, pp. 15-48.

Comisión Económica para América Latina (CEPAL) (2008), Tabasco: características e impacto socioeconómico de las inundaciones provocadas a finales de octubre y comienzos de noviembre de 2007 por el frente frío número 4, México: CEPAL/SEGOB/CENAPRED/Gobierno del Estado de Tabasco.

Gobierno del Estado de Tabasco (GET) (1988a), Tabasco a través de sus gobernantes, t. 13, Villahermosa: Gobierno del Estado de Tabasco/Instituto de Cultura de Tabasco.

Gobierno del Estado de Tabasco (GET) (1988b), Tabasco a través de sus gobernantes, t. 9, Villahermosa: Gobierno del Estado de Tabasco/Instituto de Cultura de Tabasco.

Gobierno del Estado de Tabasco (GET) (2007), ler Informe de Gobierno: Andrés Rafael Granier Melo, Villahermosa: Gobierno del Estado de Tabasco.

González Pedrero, Enrique (1983), Plan estatal de desarrollo (1983-1988), Tabasco: Gobierno Constitucional del Estado de Tabasco.

INEGI (1990), Estados Unidos Mexicanos. Censos de población, México: INEGI.

INEGI (1996), Estados Unidos Mexicanos. Cien años de censos depoblación, México, INEGI.

INEGI (1997), Anuario estadístico del estado de Tabasco, México: INEGI.

INEGI (2000a), Estados Unidos Mexicanos. Censos de población, México: INEGI.

INEGI (2000b), Estadísticas históricas de México, 2 t., México: INEGI.

INEGI (2001), Anuario estadístico del estado de Tabasco, México: INEGI.

INEGI (2004), Anuario de estadísticas por entidad federativa, México: INEGI.

INEGI (2008), Anuario estadístico del estado de Tabasco, México: INEGI.

INEGI (2010), Estados Unidos Mexicanos. Censos de población, México: INEGI.

INEGI (2011), Anuario estadístico de los Estados Unidos Mexicanos, México: INEGI.
INEGI (2012), Anuario estadístico del estado de Tabasco, México: INEGI.

Jhabvala, Firdaus y Miguel Tokeshi (coords.) (1990), Tabasco: economía y desarrollo. Elementos para la interpretación económica y social del estado, Villahermosa: Centro de Estudios de Investigación del Sureste.

Instituto de Planeación y Desarrollo Urbano del Municipio de Centro (IMPLAN) (2011), Villahermosa y el desarrollo urbano $10^{a}$ sesión, Villahermosa: IMPLAN.

Marín Olán, Pablo (2013), Modernismo hidráulico y urbanización. Estrategias adaptativas y conciencia práctica de poblaciones tabasqueñas sujetas a inundaciones recurrentes, ponencia presentada en el VII CEISAL, Memoria, Presente y Porvenir en América Latina, Universidad Fernando Pessoa, Oporto, Portugal.

Marín Olán, Pablo, Jorge Luis Capdepont Ballina y Miguel Díaz (2012), Identificación de áreas de amortiguamiento y protección ecológica: ordenamiento y gestión de la parte baja de la subcuenca de los ríos de la Sierra (informe técnico), Tabasco: El Colegio de la Frontera Sur.

Secretaría de Economía Nacional (1943), Estados Unidos Mexicanos. $6^{\circ}$ Censo de población: 1940, México: Secretaría de Economía Nacional-Dirección General de Estadística.

Secretaría de Economía Nacional (1950), Séptimo censo general de población: 6 de junio de 1950. Estado de Tabasco, México: Secretaría de Economía Nacional-Dirección General de Estadística.

Secretaría de Industria y Comercio (1963), VIII Censo general de población: 8 de junio de 1960. Estado de Tabasco, México: Secretaría de Industria y ComercioDirección General de Estadística.

Secretaría de Industria y Comercio (1971), IXCensogeneral de población: 28 de enero de 1970. Estado de Tabasco, México: Secretaría de Industria y Comercio-Dirección General de Estadística.

Secretaría de Programación y Presupuesto (1983), X Censo general de población y vivienda, 1980. Estado de Tabasco, vol. 1, t. 27, México: Secretaría de Programación y Presupuesto-INEGI.

Simmel, Georges (2005), "La metrópolis y la vida mental”, en Bifurcaciones, núm. 4, pp. 1-10. 
Tudela, Fernando (coord.) (1989), La modernización forzada del trópico: el caso de Tabasco. Proyecto Integrado del Golfo, México: El Colegio de México/Federación Internacional de Institutos de Estudios Avanzados/
Centro de Investigación y de Estudios AvanzadosInstituto Politécnico Nacional/Instituto de Investigaciones de las Naciones Unidas para el Desarrollo Social. 
Cuadro 1. Inversiones del gobierno del estado en servicios públicos en pesos (1952-1975)

\begin{tabular}{|l||c||c||c||c|c||}
\hline \multicolumn{1}{|c|}{ Servicio } & $\mathbf{1 9 5 2}$ & $\mathbf{1 9 5 8}$ & $\mathbf{1 9 6 4}$ & $\mathbf{1 9 7 0}$ & $\mathbf{1 9 7 5}$ \\
\hline \hline Educación & 3127292.10 & 5463079.68 & 57787471.12 & 74386566.00 & 144000000.00 \\
\hline \hline Salud & s. d. & s. d. & 1682966.00 & 6679970.00 & \\
\hline \hline Electricidad & s.d. & s.d. & 2246894.46 & 7862747.63 & 22635000.00 \\
\hline \hline $\begin{array}{l}\text { Agua potable y } \\
\text { alcantarillado }\end{array}$ & s. d. & s. d. & 860000.00 & $2975000.00 *$ & s. d \\
\hline \hline Caminos & 2 200 000.00 & s. d. & 28848373.26 & 33800000.00 & 118810000.00 \\
\hline
\end{tabular}

Fuente: Gobierno del Estado de Tabasco (1988: vols. 8-12). El dato de agua potable y alcantarillado que aparece en 1970 (*) en realidad corresponde a 1971. Estas cifras no incluyen las inversiones realizadas por el Ejecutivo federal, salvo las de 1975.

Cuadro 2. Aportación al PIB del estado de Tabasco por sector productivo (\%)

\begin{tabular}{|l||c||c||c|c|c|c||c||c||c||}
\hline \multicolumn{1}{|c|}{ Servicio } & $\mathbf{1 9 7 0}$ & $\mathbf{1 9 7 5}$ & $\mathbf{1 9 8 0}$ & $\mathbf{1 9 8 5}$ & $\mathbf{1 9 9 3}$ & $\mathbf{1 9 9 6}$ & $\mathbf{2 0 0 0}$ & $\mathbf{2 0 0 5}$ & $\mathbf{2 0 1 0}$ \\
\hline \hline $\begin{array}{l}\text { Primario: agricultura, } \\
\text { ganadería, } \\
\text { silvicultura y pesca }\end{array}$ & 19.5 & 11.0 & 3.8 & 6.7 & 7.5 & 7.5 & 6.8 & 2.2 & 1.6 \\
\hline $\begin{array}{l}\text { Secundario: } \\
\text { minería industria } \\
\text { manufacturera y } \\
\text { construcción }\end{array}$ & 39.2 & 59.8 & 83.4 & 43.1 & 27.3 & 31.5 & 29.8 & 58.8 & 63.8 \\
\hline $\begin{array}{l}\text { Terciario: comercio y } \\
\text { servicios }\end{array}$ & 41.3 & 29.3 & 12.8 & 50.1 & 65.2 & 61.0 & 63.4 & 39.0 & 34.6 \\
\hline
\end{tabular}

Fuente: INEGI (1997, 2001, 2008 y 2012). Los porcentajes no son exactos porque las cifras proporcionadas por el INEGI tampoco coinciden con la suma total y fueron ajustadas para los fines de este cuadro. Son útiles para darnos una idea general de la aportación al PIB por sector económico.

Cuadro 3. Porcentaje de la cobertura de servicios en Tabasco y México (1970-1990)

\begin{tabular}{|c|c|c|c|c|c|c|}
\hline \multirow{2}{*}{ Servicio } & \multicolumn{2}{|c|}{1970} & \multicolumn{2}{|c|}{1980} & \multicolumn{2}{|c|}{1990} \\
\hline & México & Tabasco & México & Tabasco & México & Tabasco \\
\hline Energía eléctrica & 58.85 & 32.22 & 74.85 & 52.27 & 87.52 & 85.18 \\
\hline Agua entubada (potable) & 61.02 & 34.23 & 70.67 & 41.76 & 79.39 & 58.33 \\
\hline Alcantarillado (drenaje) & 41.52 & 25.62 & 51.00 & 39.40 & 63.63 & 63.22 \\
\hline Viviendas con pisos de tierra & 41.07 & 61.99 & 26.45 & 37.41 & 19.46 & 13.50 \\
\hline Viviendas con paredes de cemento & 44.15 & 30.80 & 56.10 & 45.54 & 69.53 & 64.49 \\
\hline
\end{tabular}

Fuente: INEGI (1996; 201-206, 231-236 y 263-268). 
Gráfica 1. Población rural y urbana de Tabasco (1950-2010)

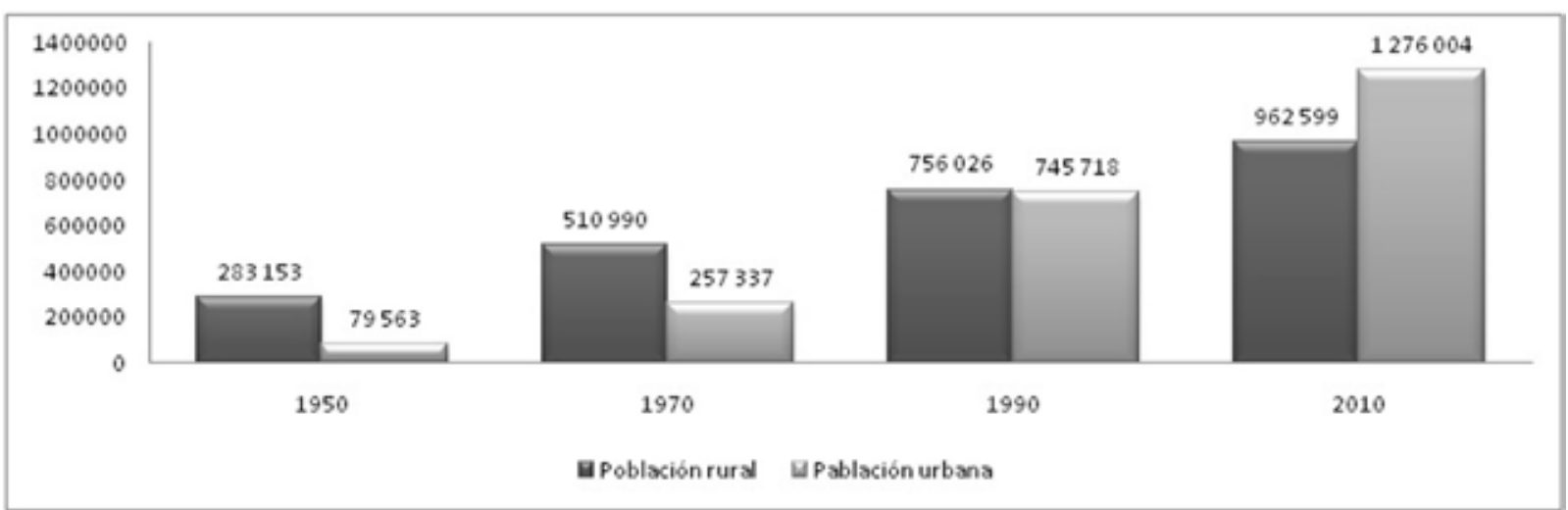

Fuente: INEGI (1996).

Gráfica 2. Crecimiento poblacional de Villahermosa (1940-2010)

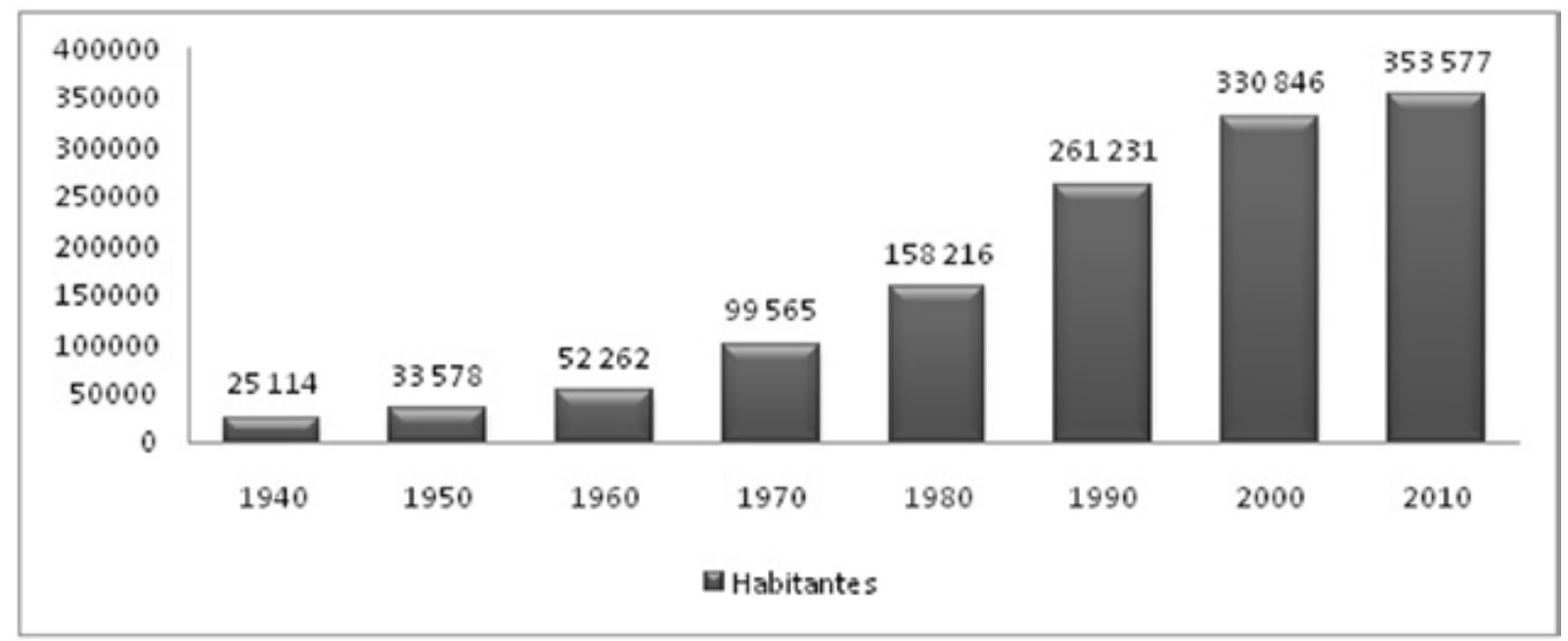

Fuente: INEGI (2002). 
Mapa 1. Villahermosa y las ciudades satélites proyectadas por el municipio de Centro

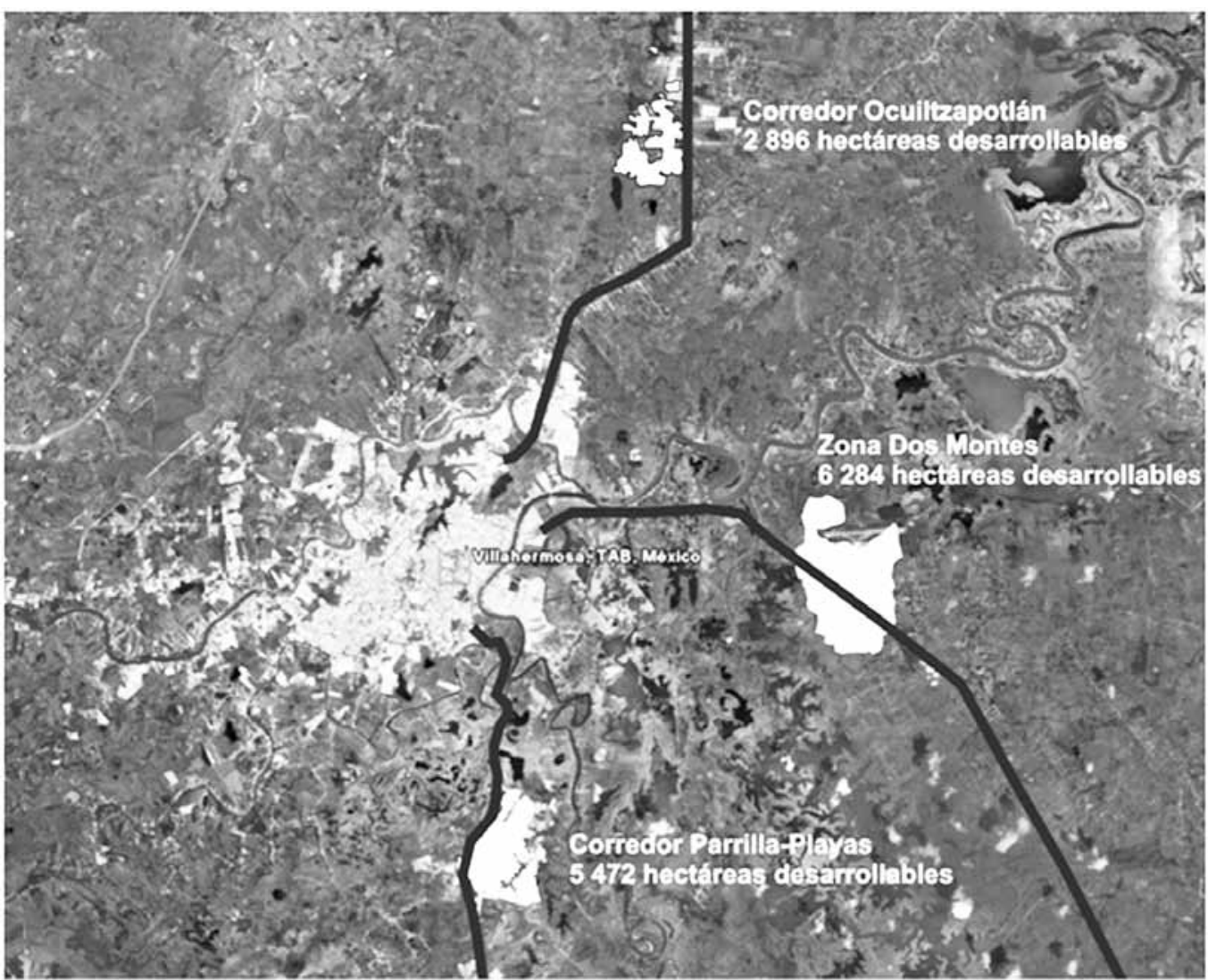

Fuente: IMPLAN (2011). 